\title{
TRATAMENTO DE EFLUENTE DE INDÚSTRIAS DE LATICÍNIOS ATRAVÉS DOS PROCESSOS ADSORTIVOS COM ARGILAS SÓDICAS
}

\author{
J. V. F. L. CAVALCANTI ${ }^{1}$, C. S. ROCHA ${ }^{1}$, THIBÉRIO SOUZA², M. A. MOTTA SOBRINHO ${ }^{2}$, O. \\ S. BARAÚNA ${ }^{3}$ \\ ${ }^{1}$ Universidade Federal Rural de Pernambuco, Unidade Acadêmica de Garanhuns \\ ${ }^{2}$ Universidade Federal de Pernambuco, Departamento de Engenharia Química \\ ${ }^{3}$ Instituto de Tecnologia de Pernambuco \\ E-mail para contato: jorgevcavalcanti@ig.com.br
}

\begin{abstract}
RESUMO - Esta pesquisa iniciou com o tratamento de uma argila da região da Boa Vista, Município de Campina Grande/PB, a Argila Chocolate, visando a substituição dos seus vários cátions da região intercamadas por cátions sódio, objetivando a expansão da mesma. Neste trabalho foi realizado o incremento do teor de sódio nas argilas por tratamento com carbonato de sódio, seguindo um planejamento $2^{4-1}$, pela variação da temperatura, concentração de sódio e tempo de contato argila/solução sódica. A argila sódica que revelou melhor propriedade tixotrópica, através de testes de quantificação da viscosidade plástica de uma suspensão pré determinada, foi submetida a ensaios de difração de raios-X e inchamento Foster, para em seguida ser utilizada como adsorvente de lactose em soluções analíticas. Os resultados do processo adsortivo se ajustaram a Isoterma de Freundlich, com ajuste de heterogeneidade $1 / n=0,314 \pm 0,053$.
\end{abstract}

\section{INTRODUÇÃO}

O leite pode ser definido como o produto oriundo da ordenha completa, ininterrupta, em condições de higiene, de vacas sadias, bem alimentadas e descansadas (Brasil - MAPA, 2011). É um produto importante na alimentação humana, por ser altamente nutritivo e de fácil acesso. O leite é formado basicamente por água e extrato seco, que engloba: as proteínas, gordura, carboidratos e sais minerais. Sua composição química varia com a espécie, raça, alimentação, idade e muitos outros fatores (Valsechi, 2001).

O soro do leite por sua vez, pode ser definido como a porção aquosa que se separa do coágulo durante a fabricação convencional do queijo. Retém cerca de $55 \%$ dos nutrientes presentes no leite. Contém proteínas solúveis, lactose, minerais e vitaminas, além de quantidades variáveis de ácido lático e nitrogênio não solúvel (Mizubuti, 1994).

O soro caracteriza-se por ser altamente poluente. Possui demanda bioquímica de oxigênio (DBO) entre 30 e 45g/litro e exige o oxigênio presente em 4.500 litros de água para despoluí-lo (Mizubuti, 1994). Parte desta demanda bioquímica deve-se a presença da lactose, pois sua 
decomposição nos corpos d'água requer um alto consumo de oxigênio, contribuindo para o aumento da DBO. O despejo dos efluentes sem tratamento prévio traz diversas consequências, como a redução de chance de vida dos peixes e aumento da vegetação aquática (Ferreira, 2007).

Uma alternativa ao uso de processos biológicos na redução da carga orgânica, como tratamento terciário do efluente da indústria de laticínios é o uso de argila esmectítica sódica para adsorção da lactose. As argilas são amplamente utilizadas em diversos segmentos, devido as suas atraentes propriedades como inchamento, adsorção, plasticidade, etc (Paiva et al, 2008).

Este trabalho teve como objetivo geral o preparo do material adsorvente e sua utilização para adsorção da lactose, importante contaminante orgânico presente no efluente de Indústrias de Laticínios, em especial no Soro de Leite.

\section{MATERIAIS E MÉTODOS}

\subsection{Preparo do Material Adsorvente e Sua Caracterização}

$\mathrm{O}$ tratamento da argila com carbonato de sódio foi realizado com uma proporção de $50 \mathrm{~g}$ de argila Chocolate in natura com $500 \mathrm{~mL}$ de água deionizada e $5 \mathrm{~mL}$ (ou 2,5mL) de uma solução 265 g. $\mathrm{L}^{-1}$ deste sal, agitando a dispersão a $800 \mathrm{RPM}$, durante $3 \mathrm{~h}$ (ou 1,5h), a uma temperatura $45^{\circ} \mathrm{C}$ (ou $25^{\circ} \mathrm{C}$ ), em um "balão de três bocas" com controle de temperatura e agitação. A dispersão foi filtrada à vácuo e o resíduo foi posto em uma estufa com circulação forçada de ar à $100{ }^{\circ} \mathrm{C}$ durante $24 \mathrm{~h}$. Em seguida, a argila sódica foi destorroada em almofariz e peneirada (\# 0,075 mm). Finalmente, foi realizado o ensaio da viscosidade plástica da argila sódica segundo as Normas N2604 e N2605 da Petrobras. A Tabela 01 sumariza o planejamento realizado.

Tabela 01 - Planejamento Experimental para produção da argila sódica

\begin{tabular}{cccc}
\hline Variáveis & $\mathbf{- 1}$ & $\mathbf{0}$ & $\mathbf{+ 1}$ \\
\hline Temperatura $\left({ }^{\circ} \mathrm{C}\right)$ & 25,0 & 35,0 & 45,0 \\
Tempo de Contato $(\mathrm{h})$ & 1,5 & 2,25 & 3,0 \\
Concentração de $\mathrm{Na}_{2} \mathrm{CO}_{3}\left(\mathrm{~g} . \mathrm{L}^{-1}\right)$ & 1,32 & 1,99 & 2,65 \\
\hline
\end{tabular}

Como resposta ao planejamento, foi realizada a quantificação da viscosidade plástica da suspensão em água desta argila (4,86\% em massa) e seu respectivo inchamento Foster (1 g de argila sódica em $50 \mathrm{~mL}$ de água deionizada em uma proveta de $100 \mathrm{~mL}$ ). Além da Difração de Raio-X, para verificar a expansão do espaçamento basal. Tanto a verificação da viscosidade plástica, como o inchamento Foster, estão diretamente correlacionados com o ganho de expansão do material adsorvente, potencializando sua propriedade de remoção de contaminantes em meio aquoso. 


\subsection{Estudo Adsortivo}

Para o estudo adsortivo, foram preparadas 5 soluções de lactose (de $100 \mathrm{~mL}$ cada), de concentrações iniciais variando de 4 a 5\% em massa de soluto (4,00/4,25/4,50/4,75/5,00\%).

Foram realizadas bateladas de $24 \mathrm{~h}$, a $30{ }^{\circ} \mathrm{C}$, em uma mesa agitadora com controle de temperatura, utilizando-se, em diferentes experimentos, $4 \mathrm{~g}$ de argila in natura e $4 \mathrm{~g}$ de argila sódica, em cada ensaio. $\mathrm{O}$ estudo adsortivo foi realizado em erlenmeyer de $250 \mathrm{~mL}$.

Foi quantificado, por refratometria, o percentual de sólidos solúveis ( ${ }^{\circ}$ Brix) das soluções de lactose antes e depois do processo adsortivo, com um respectivo ensaio em branco para as duas argilas. A separação da mesma da solução de lactose foi realizada por centrifugação a 3000 RPM durante 9 minutos.

Com os resultados obtidos, foi plotada uma curva de equilíbrio entre o teor de lactose em fase líquida $\left(\mathrm{C}_{\mathrm{eq}}\right)$ e o teor de lactose em fase sólida $\left(\mathrm{Q}_{\mathrm{eq}}\right)$. Os resultados foram ajustados a Isoterma de Equilíbrio de Freundlich (na sua forma linear), representada pela Equação 1. Para se quantificar a concentração de equilíbrio em fase sólida, pode-se fazer o balanço material entre as fases, representada pela Equação 2.

$$
\begin{aligned}
& \log Q_{e q}=\log K+n \log C_{e q} \\
& Q_{e q}=\frac{\left(C_{0}-C_{e q}\right) V}{m}
\end{aligned}
$$

Sendo $C$ a concentração em fase líquida $\left(\mathrm{mg}^{\mathrm{L}} \mathrm{L}^{-1}\right), Q$ a concentração em fase sólida $\left(\mathrm{mg} \cdot \mathrm{g}^{-1}\right), V_{\mathrm{o}}$ volume da solução (L), $m$ a massa de adsorvente $(\mathrm{g}), K$ e $n$ parâmetros de equilíbrio associados a Isoterma de Freundlich, sendo o primeiro a constante de equilíbrio adsortivo e o segundo o termo de heterogeneidade entre a coesão de sítios ativos e o adsorvato.

\section{RESULTADOS E DISCUSSÃO}

\subsection{Preparo do Material Adsorvente e Sua Caracterização}

Os resultados para as viscosidades plásticas, pós-tratamento, está mostrado na Tabela 02 e as influências das variáveis está mostrada no gráfico de Pareto, Figura 01. Já a expansão do material pode ser visualizado pelo Inchamento Foster, Figura 02.

Os resultados indicaram que o aumento da concentração de sódio e da temperatura foram determinantes no ganho da viscosidade plástica do argilomineral. 
Tabela 02 - Resultado do Planejamento Experimental para Argila Chocolate

\begin{tabular}{ccccc}
\hline Experimento & Temperatura & Tempo & Concentração & $\begin{array}{c}\text { Viscosidade } \\
\text { Aparente }\end{array}$ \\
\hline 1 & +1 & +1 & +1 & $4,0 / 4,0$ \\
1 & +1 & +1 & -1 & $2,5 / 2,5$ \\
1 & +1 & -1 & +1 & $3,5 / 3,5$ \\
1 & +1 & -1 & -1 & $2,5 / 2,5$ \\
2 & -1 & +1 & +1 & $3,0 / 3,5$ \\
2 & -1 & +1 & -1 & $2,5 / 2,5$ \\
2 & -1 & -1 & +1 & $3,0 / 3,5$ \\
2 & -1 & -1 & -1 & $2,5 / 2,5$ \\
Valor Médio & 0 & 0 & 0 & $3,0 / 3,0$ \\
\hline
\end{tabular}

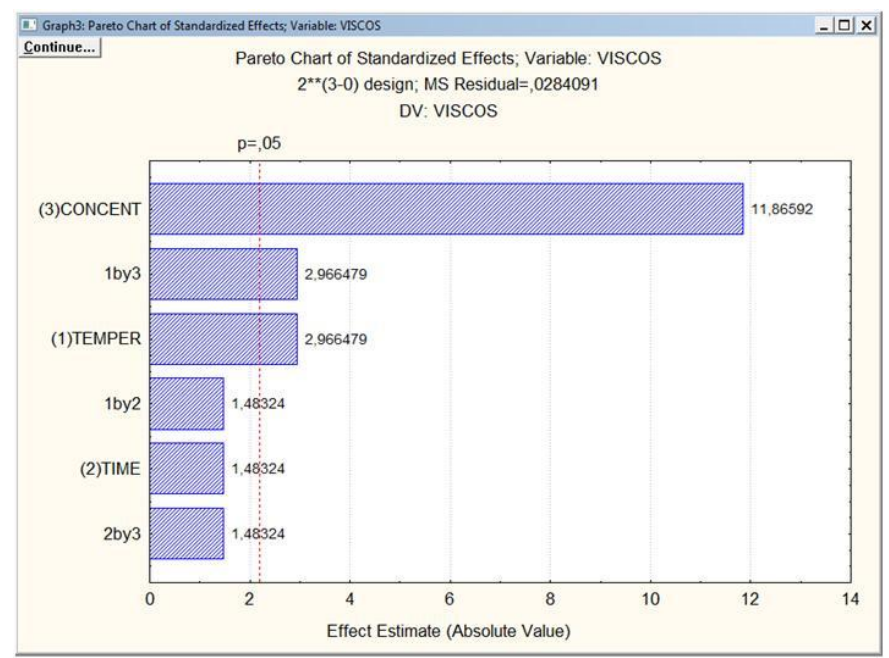

Figura 01 - avaliação da influência das variáveis do processo

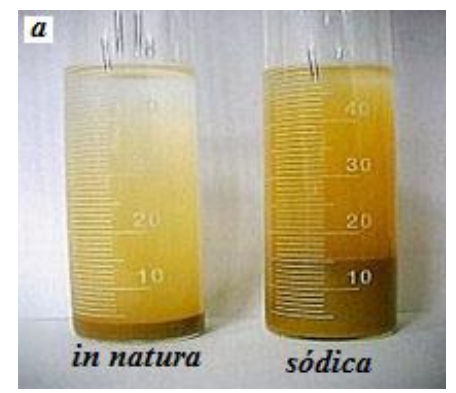

Figura 02 - Inchamento Foster 
Foi verificado um inchamento entre 14 e $15 \mathrm{~mL} \cdot \mathrm{g}^{-1}$ para este material. Valores iguais ou inferiores a $2 \mathrm{~mL} \cdot \mathrm{g}^{-1}$ são considerados como não inchamento; são considerados como inchamento baixo de 3 a $5 \mathrm{~mL} \cdot \mathrm{g}^{-1}$; de 6 a $8 \mathrm{~mL} \cdot \mathrm{g}^{-1}$ como inchamento médio; e acima de 8 mL.g ${ }^{-1}$ como inchamento alto (Diaz,1994).

Os espaçamentos basais (nm), para a argila in natura seca e hidratada, e para a argila sódica seca e hidratada, estão apresentados na Tabela 03.

Tabela 03 - Espaçamentos basais das formas in natura e Sódica (seca e hidratada)

\begin{tabular}{cc}
\hline Tipo de Argila & Espaçamento Basal (nm) \\
\hline In natura & 1,549 \\
In natura Hidratada & 1,963 \\
Sódica Seca & 1,263 \\
Sódica Hidratada & 2,454 \\
\hline
\end{tabular}

O fato da difração de Raios-X da argila sódica ter revelado um pico de 1,260 nm, ocorreu porque a amostra foi submetida a uma secagem à temperatura de $100{ }^{\circ} \mathrm{C}$, por um tempo longo para permitir o peneiramento. Ou seja, devido às condições bruscas de secagem, houve uma redução da umidade na região intercamadas. Porém, em condições de hidratação, houve uma expansão considerável deste argilomineral.

\subsection{Estudo Adsortivo}

O resultado da isoterma linear de Freundlich (equação 2), para as duas argilas (in natura e sódica), está apresentado na Figura 03.

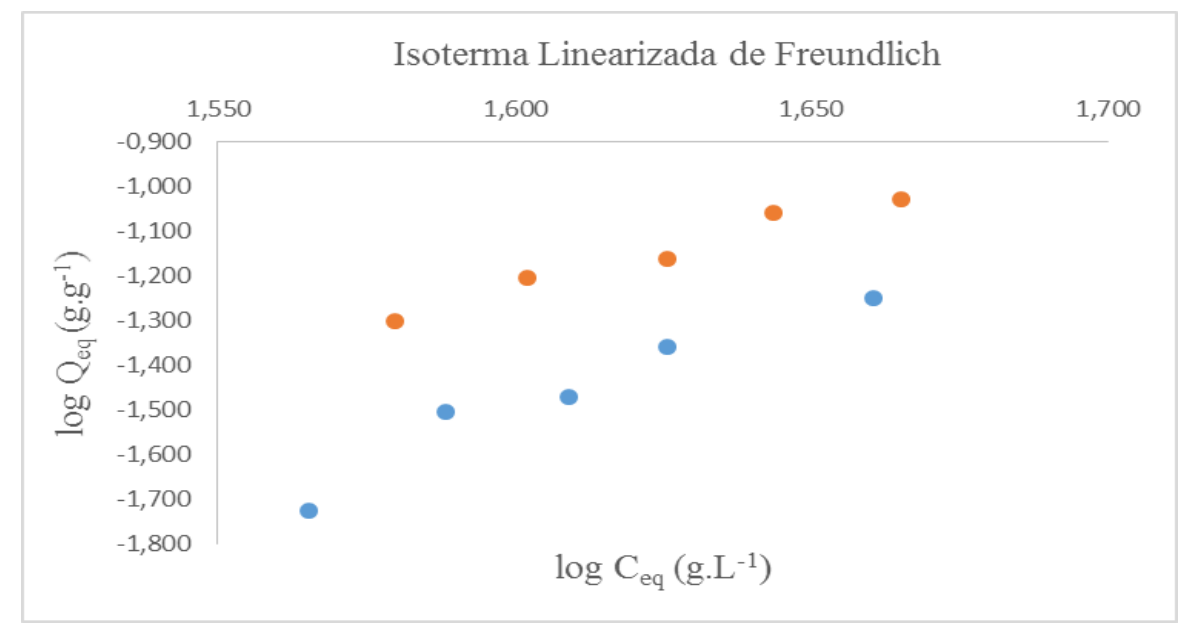

Figura 03 - Isoterma de Freundlich (• para a argila sódica e • para a argila in natura) 
Os resultados indicaram uma constante de equilíbrio $K=4,027.10^{-4} \mathrm{~mL} \cdot \mathrm{g}^{-1}$ e uma constante de heterogeneidade $1 / n=0,314 \pm 0,053$, para a argila sódica, representada pela reta superior. Os resultados também mostraram que a argila sódica, comparada com a argila in natura, foi um adsorvente mais eficiente, com capacidade adsortiva superior a $100 \mathrm{mg}$ de lactose $\mathrm{g}^{-1}$ de argila na saturação.

\section{CONCLUSÃO}

Realizado o planejamento experimental, foi possível diminuir a quantidade de ensaios e analisar a influência das variáveis independentes para a produção da argila sódica, com ampliação do espaçamento basal de 1,963 a 2,454 nm, em condições de igual hidratação.

Os resultados experimentais mostraram-se compatíveis à isoterma de Freundlich, com um incremento considerável na capacidade adsortiva do material tratado, comparado com o material in natura.

Estes experimentos serão continuados, em diferentes condições de temperatura e $\mathrm{pH}$, visando uma melhor condição físico-química para a remoção da lactose, e posteriormente para adsorção da solução real.

\section{REFERÊNCIAS}

BRASIL. Ministério da Agricultura, Pecuária e Abastecimento. Instrução Normativa $\mathrm{N}^{\circ}$ 62, de 29 de dezembro de 2011. Dispõe sobre o regulamento técnico de identidade e qualidade do leite cru refrigerado, leite pasteurizado, coleta do leite cru refrigerado e seu transporte a granel.

DIAZ, F. R. V. Obtenção, a nível de laboratório, de algumas argilas esmectíticas organofílicas, Tese de Doutorado, Departamento de Engenharia Química, USP, São Paulo, SP (1994).

FERREIRA, I. C. S. Tratamento terciário da indústria de laticínios através da adsorção da lactose em argila esmectítica. 2007. 96 f., Dissertação de Mestrado em Engenharia Química - Escola Politécnica, Universidade de São Paulo. São Paulo, 2007.

MIZUBITY, I. Y. Soro do leite: composição, processamento e utilização na alimentação. Sem.: $C i$. Agr., Londrina, v.15, n.1, p. 80-94, março de 1994.

PAIVA, L. B.; MORALES, A. R.; DIAZ, F. R. V. Argilas organofílicas: características, metodologias de preparação, compostos de intercalação e técnicas de caracterização, Cerâmica, v.54, p. 213 226, 2008.

PETROBRAS. Viscosity for water-based fluids in oil exploration, N-2604, 1998(a).

PETROBRAS. Viscosity tests for water-based fluids in oil exploration, N-2605, 1998(b). 
VALSECHI, O. A. O leite e seus derivados. Araras, p. 36, Departamento de tecnologia agroindustrial e socioeconômica rural da Universidade Federal Rural de São Carlos, 2001. 